\title{
TSTA Piping and Flame Arrestor Operating Experience Data
}

\author{
Lee C. Cadwallader ${ }^{\mathrm{a}}, \mathrm{R}$. Scott Willms ${ }^{\mathrm{b}}$ \\ ${ }^{a}$ Idaho National Laboratory, Idaho Falls, Idaho \\ ${ }^{b}$ ITER International Organization, Cadarache, France
}

\begin{abstract}
The Tritium Systems Test Assembly (TSTA) was a facility dedicated to tritium handling technology and experiment research at the Los Alamos National Laboratory. The facility was operated with tritium for its research and development program from 1984 to 2001, running a prototype fusion fuel processing loop with 100 grams of tritium as well as small experiments. There have been several operating experience reports written on this facility's operation and maintenance experience. This paper describes reliability analysis of two additional components from TSTA, small diameter copper gas piping that handled tritium in a nitrogen carrier gas, and the flame arrestor used in this piping system. The component failure rates for these components are discussed in this paper. Comparison data from other applications are also presented.
\end{abstract}

Keywords: tritium piping, flame arrestor, failure rate.

\section{Introduction}

The failure rates of equipment are sought to support fusion safety assessment and reliability studies. When fusion experiments use tritium, the safety assessment and reliability of confinement both become more important for machine operation. It is widely regarded that the most optimum failure rate data come from the same or similar components operating in the same application as the components under examination because these components operate in the same application, they are exposed to the same operating environment and the same stressors that can lead to failures. Work is ongoing in fusion to collect the operating experiences of fusion components and apply these to the components to be used in the next generation of fusion experiments [1]. This paper presents data on tritium piping and flame arrestors that were used at TSTA.

\section{Tritium-bearing piping}

Past reliability study of the TSTA Tritium Waste Treatment (TWT) system [2] did not include the system piping due to lack of information on the piping runs used in the system. Additional data allows the TWT piping to be addressed here. The TWT piping continuously accepted gases from glovebox purges which consisted of nitrogen contaminated with tritiated water vapor and molecular hydrogen isotopes. Nominally the tritium concentration in this stream was $\sim 0.01 \mathrm{ppm}$ but it could range about two orders of magnitude higher. The TWT piping also periodically accepted gases from process piping. This could be slow, continuous venting, but generally this was brief but rapid gas streams associated with vessel and piping evacuation. These streams generally consisted of nitrogen, air, argon, hydrogen isotopes, methane, carbon monoxide, carbon dioxide, neon, helium and traces of pump oils. The amount of tritium in these streams in certain cases could be up to percent level concentrations. In the end, all source streams were manifolded together to a single TWT feed.
For the vast majority of a calendar year, the TWT feed was the nominal glovebox atmosphere exhaust $\left(\mathrm{N}_{2}\right.$ with $\sim 0.01 \mathrm{ppm}$ tritium). Given the low level of tritium in the piping, secondary confinement was not necessary. The gas lines were made primarily of deoxidized highphosphorus copper type L [3] water tubing while some stainless steel 304L or 316 was used [4] for these gas lines. The TWT copper piping used $17 \mathrm{~m}$ of $5-\mathrm{cm}$ diameter pipe, $83.5 \mathrm{~m}$ of $2.5-\mathrm{cm}$ diameter pipe, and 0.7 $\mathrm{m}$ of $1.27-\mathrm{cm}$ diameter pipe for a total of $101.2 \mathrm{~m}$ of piping of these three diameters which are all considered to be small diameter piping. Wrought copper joint fittings were used. The copper piping was typically soft soldered rather than using flanged connections [5]. 95\% tin and 5\% antimony solder was used. The typical TWT gas flow rate was $0.025 \mathrm{~m}^{3} / \mathrm{s}$. For the first half of the system the gas pressure ranged from 27 to $55 \mathrm{kPa}$ (4 to 8 psia) and temperatures were generally ambient but up to $500^{\circ} \mathrm{C}$ at the catalytic reactor, which used stainless steel pipe. For the second half of the system the pressure was nominally $0.3 \mathrm{MPa}$ at ambient temperature. The gas pressure was reduced to ambient $(79 \mathrm{kPa})$ prior to venting to the facility vent stack. The piping had some vibration, the principal vibration arising from the compressors that drew gas from the Low Pressure Receiver (LPR) tank. This tank was operated at the sub atmospheric pressure listed above so that gas flowed to the LPR from the outlet gas valves on the gloveboxes.

Detailed TWT failure data were collected during 1984 through 1989 [2]. This dataset showed that system leaks did not originate from the piping or pipe joints. The three small leaks (e.g., fractions of milliCuries of tritium released) that did occur came from a pinhole leak in a filter casing, a leak from a flexible tubing line connected to the stainless steel piping, and a corrosioninduced leak on a compressor exhaust line. During continued operation of the TWT through the start of 2003, a certain number of TWT leaks were encountered

author's email: Lee.Cadwallader@inl.gov 
but these were not believed to be from the piping or pipe joints. These small leaks were addressed through normal preventive and corrective maintenance. None resulted in an event being entered into the US Department of Energy (US DOE) Occurrence Reporting and Processing System (ORPS). The ORPS data collection holds reports from its inception in 1990 through decommissioning of TSTA in the 2000's. The TWT piping operated for over 18 years with no failures. For the mid-1984 to 1989 time frame, in those 5.5 years the TWT operated 47,531 hours [2], which averages to 8642 hours/year or all but approximately 118 hours per year. A one-week outage allowance of $168 \mathrm{~h}$ was subtracted from each year in the span of 1990-to the beginning of 2003 to conservatively account for downtimes that are not precisely known for the later years of TSTA operation. This calculation is $47,531 \mathrm{~h}+(13 \mathrm{y})(8760 \mathrm{~h}-$ $168 \mathrm{~h}$ per $\mathrm{y})=159,227$ operating hours for the TWT. The typical maximum likelihood estimate failure rate calculation, $\lambda=n / T$, where $n=$ number of failure events and $\mathrm{T}=$ total component operating time cannot be applied with $n=0$. But, an assumption can be made to use the Bayes posterior distribution where $n=0.5$ [6]. The failure rate is $\lambda=0.5 /(101.2 \mathrm{~m})(159,227 \mathrm{~h})=3.1 \mathrm{E}-08 / \mathrm{m}-\mathrm{h}$ for failures of the small diameter copper piping, including the fittings and solder joints. An upper bound failure rate with a 95\% Chi-square distribution and $2 \mathrm{n}+1$ degrees of freedom is $\lambda_{95 \%}=\chi^{2}(0.95,1) / 2 \mathrm{~T}$. The $\chi^{2}(0.95,1)=3.84$ as found from Chi-square tables [7]. The upper bound failure rate calculation is $\lambda_{95 \%}=$ $3.84 /(2 \times 101.2 \mathrm{~m} \times 159,227 \mathrm{~h})$ or $1.2 \mathrm{E}-07 / \mathrm{m}-\mathrm{h}$. The Chi-square $5 \%$ lower bound failure rate calculation for the posterior distribution uses $2 n+1$ degrees of freedom. The $\chi^{2}(0.05,1)=0.00393$ as found from Chi-square tables [7]. The 5\% lower bound failure rate, $\lambda_{5 \%}=$ $0.00393 /(2 \times 101.2 \mathrm{~m} \times 159,227 \mathrm{~h})$ or $1.2 \mathrm{E}-10 / \mathrm{m}-\mathrm{h}$. This failure rate would apply to failure modes such as leakage and pipe plugging. Large leaks from pipes are rare, so this failure mode is treated separately. Based on Eide [8] the analyst judgment average failure rate for pipe large leakage is $10 \mathrm{x}$ lower than the small leakage failure rate, or $2.9 \mathrm{E}-09 / \mathrm{h}-\mathrm{m}$. Pipe rupture is a very rare event, it is assumed to be $10 \mathrm{x}$ less than the large leakage failure mode value, or $2.9 \mathrm{E}-10 / \mathrm{h}-\mathrm{m}$.

Other tritium piping failure rate data $[9,10]$ were reviewed for comparison to determine if this leakage failure rate is accurate. Unfortunately, Pinna [9] did not address piping. Gordon [10] gave an engineering judgment of $0.01 /$ year for his plant's tritium piping leakage. The pipe material was stainless steel. Gordon [10] provided enough information to allow estimation of a piping failure rate from his estimated $0.01 /$ year frequency; the result was $1.9 \mathrm{E}-08 / \mathrm{h}-\mathrm{m}$. This is a factor of 1.6 less than the TSTA value. Since Gordon's value was an engineering judgment rather than experience, and the pipe materials were different, failure rates from other operating experiences were sought for comparison. A literature search was undertaken to identify gas piping failure rate data from commercial applications. It was found that gas piping datasets are few, dealing mainly with fuel gases (natural gas, propane, etc.) at ambient temperature and pressures of 1.0 $\mathrm{MPa}$ and higher. The piping used to transmit and distribute these gases is carbon steel rather than copper, is often larger than $0.1 \mathrm{~m}$ diameter (e.g., 0.3 to $\sim 1 \mathrm{~m}$ diameter) [11]. Small diameter gas distribution piping is not well reported in the literature; no datasets were found on commercial small diameter gas piping.

Hale [12] gave small $(<50 \mathrm{~mm}$ diameter $)$ refrigerant/coolant piping an 'all modes' failure rate of $1.2 \mathrm{E}-07 / \mathrm{h}-$ foot, or $3.9 \mathrm{E}-07 / \mathrm{h}-\mathrm{m}$. This value is a factor of 12.6 larger than the TSTA value. Hale's value was calculated from industrial refrigerant (e.g., Freon) piping experience, which is copper piping probably operating at $<4$ bar. Since refrigeration systems are built to different standards than radioactive gas pipe and they experience many thermal cycles (e.g., -15 to $60^{\circ} \mathrm{C}$ ), these attributes could result in the high failure rate reported by Hale [12]. In any case, the refrigeration piping failure rate was greater than the TSTA value.

The TSTA piping failure rate value from operating experience is a good comparison with the Gordon [10] engineering judgment value and both of these tritium piping values are less than other published values for small diameter gas piping. The conclusion is that the TSTA value is reasonable to use when modeling tritium piping. If the designer finds this failure rate is predicting leakage due to the lengths of pipe in use, then secondary containment [13] may address the concern.

\section{Flame Arrestors}

The feed stream to the TWT was described above. The TWT design prudently used a dry-type deflagration flame arrestor in the main piping from the LPR. This flame arrestor was designed to reside in-line in the gas stream and passively remove heat from any flowing, burning gas so that the gas would cool below the point of supporting a flame. These units are typically either a set of wire mesh screens or a crimped metal ribbon that forms flow channels gas must traverse [14]. A drawing of a crimped metal flame arrestor is given in Figure 1. The TWT flame arrestor operated over the life of the system and did not leak, or become fouled. The TWT system operated almost continually for over 18 years (February 1984 to early 2003, or 159,227 hours as calculated above), and there were no failures of this arrestor unit cited in Cadwallader [2], which examined early operation, or in the DOE ORPS database, which collected information from TSTA mid-life to decommissioning. Again using Atwood [3] guidance on zero failure events, the failure rate for this unit is calculated as $\lambda=0.5 / \mathrm{T}$, where $\mathrm{T}$ is the total operating time of the component. Then $\lambda=0.5 /(159,227 \mathrm{~h})(1$ arrestor) or $3.1 \mathrm{E}-06 /$ hour. This failure rate would be applied to any hourly failure mode; the main hourly failure modes for arrestors are leakage and plugging. The upper and lower bounds for this failure rate are calculated by the Chi-square distribution like in the piping section. An upper bound failure rate is 
$1.2 \mathrm{E}-05 / \mathrm{h}$. The Chi-square $5 \%$ lower bound failure rate calculation gives $3.2 \mathrm{E}-07 / \mathrm{h}$.

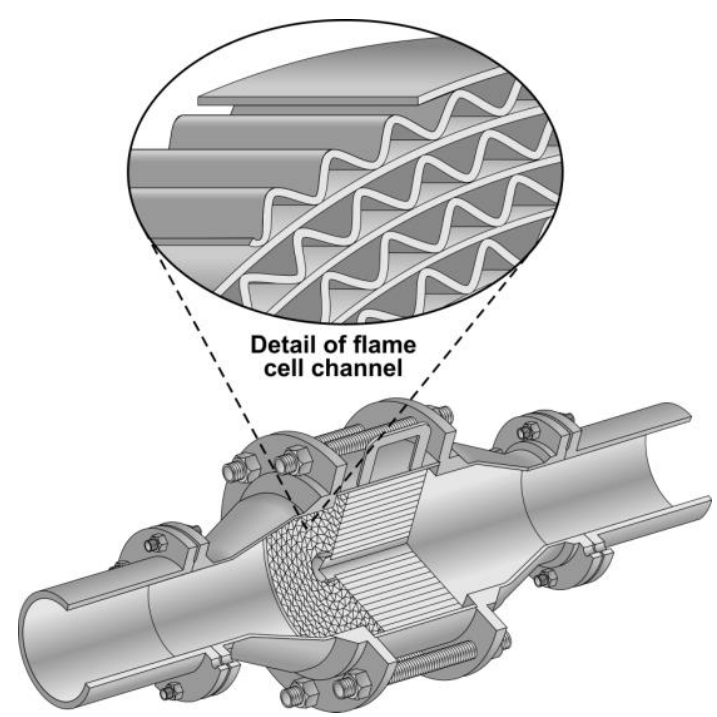

Fig. 1. Sketch of an industrial crimped metal ribbon, in-line deflagration flame arrestor.

Fortunately, TSTA did not have any combustion flame fronts created in the TWT piping. However, this means that the flame arrestor was never challenged to operate. With no demands to function, then no 'failure to function on demand' failure rate can be calculated from the TSTA operating experience. No demand failure rate was found in the literature for flame arrestors used in other industries. Grossel [14] noted that arrestors do fail, so experience data was sought to quantify a failure on demand value.

Wilson [15] reported results of tests of crimped metal ribbon and other types of arrestors. This report is of interest due to the type of arrestors tested and the large number of tests performed. The crimped metal design results are reviewed here because this is the type believed to be used at TSTA and Grossel [14] stated this is the most widely used design. Examining the crimped metal arrestor performance in tests with butane and gasoline vapor, the arrestors stopped flame propagation past the arrestor in all but one case where the flame speed was very high. In 34 tests there was one failure, giving a demand failure rate of $1 / 34=2.9 \mathrm{E}-02$ per demand. An upper bound failure rate with a $95 \%$ Chisquare distribution and $2 n+2$ degrees of freedom with $\mathrm{n}=1$ failure on demand would be $\lambda_{95 \%}=\left(\chi^{2}(0.95,4) / 2 \mathrm{D}\right)$, that is, $\lambda_{95 \%}=(9.49) /[2 \cdot 34]$ or $1.4 \mathrm{E}-01 /$ demand. The lower bound failure rate would be calculated with $2 \mathrm{n}$ degrees of freedom, $\lambda_{5 \%}=\left(\chi^{2}(0.05,2) / 2 \mathrm{D}\right)$, that is, $\lambda_{5 \%}=(0.103) /[2 \times 34]$ or $1.5 \mathrm{E}-03 /$ demand. The 34 tests varied the gas mixture, the gas pressure and temperature, and flame speed conditions within the arrestor ratings and the arrestors functioned well. In the single test where an arrestor failed to stop flame propagation, the flame speed was $20 \%$ greater than typical. The fastmoving flame front did not cool enough as the burning gas traversed the arrestor channels, so flame passed through and continued to burn on the downstream side of the arrestor.

It is desirable to compare the TSTA flame arrestor failure rate result to other flame arrestor failure rates to determine if the TSTA operating experience is sufficient to provide data on a mature component in another tritium application. Flame arrestor failure rates were difficult to find in the literature. Some operating experience data were found from the air intake flame traps on diesel engine systems $[16,17]$. These units are mounted in a flanged housing in the air intake line and are typically the crimped metal dry-type flame arrestor. The engine inlet air is close to atmospheric pressure and temperature, which is fairly similar to TSTA TWT gas. Combining the Hughes [16] and Mysore [17] reports, over the three years of 2010-2012, there were 1,030 diesel engines in continuous use, each with one air intake flame trap. This diesel dataset is a snapshot in time from mature units in field operation, so the typical concern about new component 'infant mortality' skewing the data is not believed to be an issue with this dataset. This period of time and large number of components in the sample should give a good result. There were 17 failures in the first two years of the study and 11 failures in the third year, for a total of 28 flame arrestor failures. The run time of each diesel engine was not given, but the engines were meant for continuous operation, supporting three-shift daily operation at mines. A week of preventive maintenance outage was assumed for each engine per year, so $8760 \mathrm{~h}-168 \mathrm{~h}=8592$ operating hours per year. The basic failure rate is assumed to be $\lambda=\mathrm{n} / \mathrm{T}$, so $\lambda=28$ failures $/(1,030$ units $\times 3 \mathrm{y} \times 8592 \mathrm{~h} / \mathrm{y})$ or $1.1 \mathrm{E}-06 /$ unit-hour for failure to operate. The failure rate $95 \%$ and $5 \%$ confidence bounds for this estimate are found from the Chi-square distribution with $n=28$ failures. The upper bound failure rate is $1.4 \mathrm{E}-06 / \mathrm{h}$. The $5 \%$ lower bound failure rate is $7.6 \mathrm{E}-07 / \mathrm{h}$. Hughes [16] and Mysore [17] did not discuss any flame front suppression events so it is assumed that none occurred in the 3-year time interval. No flame arrestor tests were mentioned. Therefore, there were no challenges to these flame arrestors and no estimate of a failure on demand has been calculated.

The TSTA flame arrestor value of $3.1 \mathrm{E}-06 / \mathrm{h}$ and the diesel air intake flame arrestor value of $1.1 \mathrm{E}-06 / \mathrm{h}$ are a factor of 2.8 apart. Failure rates that compare within a half-order of magnitude $(\sim 3.2)$ are regarded as a good comparison, and failure rates that compare within a factor of 10 are regarded as a fair comparison [18]. The hourly failure rate for the TSTA flame arrestor compares well to other experiences and is a reasonable value to apply to other flame arrestors in a tritium plant environment.

\section{Conclusions}

Failure rates for tritium piping and for flame arrestors have been estimated from TSTA TWT system operating experience. The failure rates are given in Table 1 below. 
These failure rates from TSTA operating experience gave good comparisons to other failure rates from comparable and matured industrial equipment in the most similar applications to the TWT, giving confidence that these estimates from TSTA are also mature and can be applied to other tritium-bearing components operating under similar conditions. The TSTA TWT flame arrestor was never challenged to operate. Some testing data on industrial flame arrestors were used to calculate a demand failure rate for crimped metal ribbon units. These failure rates from TSTA can be applied to other tritium systems whose operating parameters are similar to those from TSTA. Work will continue in reducing TSTA operating experiences to component failure rate values.

Table 1. Failure Rate Values for TWT tritium-bearing piping and flame arrestor components.

\begin{tabular}{|l|l|c|c|c|}
\hline Component & \multicolumn{1}{|c|}{ Failure Mode } & $\begin{array}{c}\text { Average Failure } \\
\text { Rate }\end{array}$ & $\begin{array}{c}5 \% \text { Lower bound } \\
\text { Failure Rate }\end{array}$ & $\begin{array}{c}\text { 95\% Upper bound } \\
\text { Failure Rate }\end{array}$ \\
\hline \multirow{3}{*}{ TSTA TWT copper piping } & Small leakage & $3.1 \mathrm{E}-08 / \mathrm{h}-\mathrm{m}$ & $1.2 \mathrm{E}-10 / \mathrm{h}-\mathrm{m}$ & $1.2 \mathrm{E}-07 / \mathrm{h}-\mathrm{m}$ \\
\cline { 2 - 5 } & Large leakage & $3.1 \mathrm{E}-09 / \mathrm{h}-\mathrm{m}$ & $1.2 \mathrm{E}-11 / \mathrm{h}-\mathrm{m}$ & $1.2 \mathrm{E}-08 / \mathrm{h}-\mathrm{m}$ \\
\cline { 2 - 5 } & Plugging & $3.1 \mathrm{E}-08 / \mathrm{h}-\mathrm{m}$ & $1.2 \mathrm{E}-10 / \mathrm{h}-\mathrm{m}$ & $1.2 \mathrm{E}-07 / \mathrm{h}-\mathrm{m}$ \\
\cline { 2 - 5 } & Rupture & $3.1 \mathrm{E}-10 / \mathrm{h}-\mathrm{m}$ & $1.2 \mathrm{E}-12 / \mathrm{h}-\mathrm{m}$ & $1.2 \mathrm{E}-09 / \mathrm{h}-\mathrm{m}$ \\
\hline \multirow{3}{*}{ TSTA TWT flame arrestor } & Plugging & $3.1 \mathrm{E}-06 / \mathrm{h}$ & $3.2 \mathrm{E}-07 / \mathrm{h}$ & $1.2 \mathrm{E}-05 / \mathrm{h}$ \\
\cline { 2 - 5 } & Leakage & $3.1 \mathrm{E}-06 / \mathrm{h}$ & $3.2 \mathrm{E}-07 / \mathrm{h}$ & $1.2 \mathrm{E}-05 / \mathrm{h}$ \\
\hline Industrial flame arrestor & Fail on demand & $2.9 \mathrm{E}-02 / \mathrm{d}$ & $1.5 \mathrm{E}-03 / \mathrm{d}$ & $1.4 \mathrm{E}-01 / \mathrm{d}$ \\
\hline
\end{tabular}

\section{Acknowledgments}

This material is based upon work supported by the U. S. Department of Energy Office of Science, Office of Fusion Energy Sciences, under the DOE Idaho Operations Office contract number DE-AC0705 ID14517.

\section{References}

[1] T. Pinna et al., Operating experiences from existing fusion facilities in view of ITER safety and reliability, Fusion Engineering and Design 85 (2010) 1410-1415.

[2] L. C. Cadwallader and M. A. Stolpe Gavett, Tritium Waste Treatment System Component Failure Data Analysis from June 18, 1984 to December 31, 1989, EGG-FSP-8973, 1990.

[3] Standard Specification for Seamless Copper Water Tube, ASTM B88-09, ASTM International, West Conshohocken, PA, 2009.

[4] Safety Analysis Report for the Tritium Systems Test Assembly, revision 1, TSTA-SAR R1, Los Alamos National Laboratory, April 1996, section 4.8.

[5] R. V. Carlson et al., Operating Experience with the Tritium Systems Test Assembly Tritium Waste Treatment System Fusion Technology 8 (1985) 2184-2189.

[6] C. L. Atwood et al., Handbook of Parameter Estimation for Probabilistic Risk Assessment, NUREG/CR-6823, 2003, section 6.2.2.5.2.

[7] P. D. T. O'Connor, Practical Reliability Engineering, second edition, John Wiley \& Sons, New York, 1985.

[8] S. A. Eide et al., Industry-Average Performance for Components and Initiating Events at U.S. Commercial Nuclear Power Plants, NUREG/CR-6928, 2007, section A.2.33.

[9] T. Pinna et al., Collection and Analysis of Data Related to Fusion Machines (JET and TLK) Operation Experience on Component Failures, FUS-TN-SA-SE-R-058, ENEA, February 2003.

[10] C. Gordon, Joint european torus active gas handling system preliminary safety analysis report, JET-TN $(88) 02$, February 1988.

[11] R. J. Eiber and D. J. Jones, An Analysis of Reportable Incidents for Natural Gas Transmission and Gathering Lines, June 1984 through 1990, American Gas Association, Committee NG-18 report 200, August 1992.

[12] P. S. Hale, Jr., R. G. Arno, and S. J. Briggs, Operational Maintenance Data for Power Generation Distribution and HVAC Components, IEEE Transactions on Industry Applications 35 (1999) 282-297.

[13] L. Cadwallader and T. Pinna, Reliability estimation for double containment piping, Fusion Science and Technology 64 (2013) 351-356.

[14] S. S. Grossel, Deflagration and Detonation Flame Arresters, American Institute of Chemical Engineers, New York, 2002, chapters 3, 5.

[15] R. P. Wilson and D. P. Crowley, Performance of Commercially Available Flame Arresters for Butane/Air and Gasoline/Air Mixtures, CG-D-72-78, NTIS ADA062948, US Coast Guard, September 1978.

[16] L. Hughes, Summary of Reported Incidents, In-Service Failure of Explosion-Protected Diesel Engine Systems, ExDES Report 120215, New South Wales Government Department of Trade \& Investment, Mine Safety, Australia, February 2012.

[17] K. Mysore, Explosion protected diesel engine systems failures analysis report, MU13-03, New South Wales Government Department of Trade \& Investment, Mine Safety, Australia, October 2013.

[18] L. C. Cadwallader and T. Pinna, Progress Toward a Component Failure Rate Data Bank for Magnetic Fusion Safety Proceedings of the International Topical Meeting on Probabilistic Safety Assessment (PSA '99), August 2226, 1999, Washington, DC, ANS (1999) 11-17. 